Ankara Ecz. Fak. Mec.

12. 29 (1982) j. Fac. Pharm Ankara

12. 29 (1982)

\title{
Farklı Gereçlerle Hazırlanan Granülelerin Tabletin Fiziksel özellikleri Üzerine Etkisinin İncelenmesi
}

\author{
Untersuchung des Einflusses von Granulaten, Welche durch die \\ verchiedenen Geraete hergestellt wurden, auf die physikalischen \\ Eigenschaften von Tabletten
}

Tamer BAYKARA* ve Nevin ÇELEB I *

G İ R İ Ş

Tablet imalatında standartlaştırılmamış her türlü çalışma koşulu, tabletin fiziksel özelliklerinde farklı bir karakter olarak karşımıza çıkmaktadır (1). Örneğin imalat sırasında granülenin maruz kalacağı mekanik zorlamalar (sürtünme vs) granülenin partikül büyüklüğü ve dağılımının değişmesine neden olmakta, bu da granülenin kötü akma özelliği kazanmasına, küme dansitesinin değişmesine ve tabletin basım karakterinde değişkenliklere ve tabletten tablete değişen ağırlık sapmalarına neden olmaktadır (2,3). Yaş yöntemle hazırlanan granülelerin kırılganlıkları üzerine etkiyen faktörler, a) Kullanılan bağlayıcı maddelerin cins ve derişkenlikleri (4-9), b) Elenmiş yaş granülenin yüksek sıcaklıkta ani olarak kurutulması, granülenin kırılganlığının artmasına neden olmakta (10) ve birbirini takip eden işlemler sırasında partiküller arasındaki sürtünmeler nedeniyle granülenin partikül büyüklükleri ve dağılımları kontrol edilemiyecek bir biçimde değişmektedir. Bu da teknolojik uygunluktan tutunda, ilacın yararlılı̆̆ına kadar uzanan olumsuz sonuçların meydana gelmesine neden olmaktadır (12-15). c) Üçüncü bir

Redaksiyona verildiği tarih: 22 Mart 1982.

* Farmasötik Teknoloji Kürsüsü, Eczacılık Fakültesi. Ankara Üniversitesi. 
faktör de granülenin içermesi istenilen nem miktarıdır (11,16). d) Granülenin kurutulmadan önce ve kurutulduktan sonra elendikleri eleklerin gözenek büyüklükleri arasındaki oran (17), bu gün literatürde belirtilmektedir.

Tektür dağllımlı partiküllere sahip toz veya granüle, eğer az basınçlı yeterli sertlikte tablet veriyorsa; bu teknolojik bakımdan erişilmek istenilen en iyi (optimum) bir sonuçtur. Bazen granülelerin partikül büyüklüğü dağılım sınırının dar bir aralıkta olmadı̆̆ 1 ve bu dağılımın tozun içinde varyasyon gösterdiği hallerde, yeterli tablet sertliği (Druckfestigkeit) tabletin kapak-atmaya meyline bir ölçüt teşkil etmemektedir. Bu gibi fiziksel değişkenliklerin çoğu, granülenin partikül büyüklüğü ve dağılımının değişmesi ile yakından ilgilidir (18-22).

Tablet imalatı sırasında kurutulmuş granüleler, diğer karıştırma işlemleri sırasında ve de bunu takiben basımda, tablet makinasının titreşimi ile birbirlerine sürtünerek, kırılmaya-ufalanmaya maruz kalmaktadırlar. Böylece yine partikül büyüklüğ̈ ve dağılımı ile partikül şekli kendiliğinden değişikliğe uğramaktadır (22).

Tablet granülesinin sütünmeye karşı direncini, yani kırılganlığını (friabilité) nicel olarak saptamak için önce, iki plaka arasına yerleştirilmiş granüle kütlesinin üzerine uygulanan kuvvete karş1 granülenin göstermiş olduğu direnç saptanmıştır (2,3,23). FONNER (24) ve arkadaşları, tablet imalatı sırasında granüle kırılganlığının, statik şekilden çok sürtünme halinde, yani gerçeğe benzetilmiş bir biçimde saptanması gerektiğini görmüşlerdir. Bu amaçla, kapalı bir kap içinde granüle, belirli bir süre çalkalanarak karıştırılmış ve belirli meş arasındaki partiküllerin ağırlıklarındaki artma tesbit edilmiştir. Daha sonra Roche Friabilatörönün bu amaçla ilk kez kullanılması, MARKS (25) ve arkadaşları tarafından ve sonuçlarının geliştirilmesi de HUNTER (26) tarafından yapılmıştır. Son olarak, RU BINSTEIN (27) ve arkadaşları Roche Friabilatöründe belli süre ve devirde aşınmaya-kırılmaya maruz bıraktıkları granüleyi sonradan elek analizine tabi tutarak, partikül büyüklükleri dağılımında yararlanarak granülenin kırılganlık indeksini saptamışlardır.

Kırılganlık indeksi $=\frac{\text { Testten sonra partiküllerin çap } 1 \text { (Medyan) }}{\text { Testten önce partiküllerin çapı }(\text { Medyan })} \times 100 \%$ 
Yukarıdaki eşitlikten hesaplanan değer, granülenin kırılganlık indeksini bize vermektedir. Granüle ne kadar kırılgan ise, bu değer o denli sıfıra doğru yaklaşmaktadır. Sayı l'e yakınsa granülenin kırılganlı̆̆ı azdır. Bu değer birden uzaklaşıp sıfıra yaklaştıkça, kırılganlık da o denli fazlalaşmaktadır.

Biz bu araştırmamızda, aynı koşullarda ve yaş yöntemle, fakat granüle kütlesinin farklı gereçlerle hazırlandığ 1 hallerde, granülenin kırılganlığında herhangi bir değişkenlik olup olmadığını göstermeye, eğer varsa, bu değişkenliğin, basılan tabletin fiziksel özelliklerine ne ölçüde yansıyabileceğini göstermeye çalıştık.

DENEYSEL B Ö L Ü M

\section{Granülenin Hazırlanması:}

Granüle formülü:

\begin{tabular}{|c|c|}
\hline Laktoz. & 390 \\
\hline Patates nişastası. & .100 \\
\hline Bağlayıcı \% 4 a/h PVP Çöz. & .136 .3 \\
\hline Kaydırıcı-Kaypaklaştırıcı & $\% 2$ \\
\hline
\end{tabular}

Kaydırıcı-kaypaklaştırıcı olarak aşağıda formülü verilen karışım kullanılmıştır.

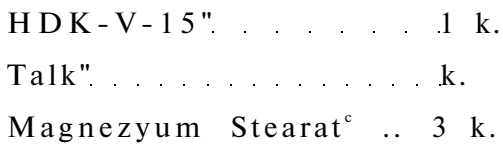

Tozların pat kıvamına getirilmesi işlemi; melanjör ${ }^{d}$ ve planet $^{\mathrm{e}}$ karıştırıcılarda ayrı ayrı yapıldı. İki faklı gereçle hazırlanmış granül elde edildi.

Laktoz ${ }^{\mathrm{f}}$, patates nişastası ${ }^{\mathrm{g}}$, küp karıştırıcıda ${ }^{\mathrm{h}}, 30$ dakika karıştırılıp, sonra melanjörde pat kıvamına gelinceye kadar \% 4 a/h
a) Hochdisperse Kieselsaeure, Wecker Chem. GmbH, B. Almanya.
b) B D H, Pool, İngiltere,
c) Riedel, B. Almanya,
d) Erweka, Laborkneter, Type LK5, B. Almanya,
e) Erweka, Planetenrührwerk, Type PRS, B. Almanya,
f,g) Farmasötik kalite,
h) Erweka, Kubusmischer, Type KB 15/UG, B. Almanya, 
lık PVP ${ }^{\mathrm{i}}$ çözeltisi ilave edildi. Daha sonra $1.6 \mathrm{~mm}$ lik elekten ${ }^{1}$ geçirilerek, hava cereyanlı etüvde $50^{\circ} \pm 2 \mathrm{C}$ de, 1.5 saat süre ile kurutuldu. Kurutulduktan sonra granüleler, $1.6 \mathrm{~mm}$. lik elekten geçirildi. Böylece Formül I oluştu. Pat kıvamına getirme işlemi bu kez de melanjör yerine, planet karıştırıcı kullanılarak yapıldı. Formül I deki diğer işlemlerin hepsi aynen tekrarlandi. Formül II oluştu.

Formül I ve Formül II den 100 er g alınıp, partikül büyüklüğü analizi için vibrasyon eleğinde ${ }^{1}$, teker teker elek analizine tabi tutuldu ${ }^{\mathrm{m}}$. Böylece Formül Ia ve Formül IIa oluşur.

Formül I ve Formül II granülelerinden 100 er g alınıp, Roche Friabilatöründe ufalanma-aşınma işlemine tabi tutuldu" . Ufalanma -aşınmaya maruz kalan bu granülelerde, yukarıdaki gibi partikül büyüklüğü analizi yapıldı. Aynı tipe ait olan elek fraksiyonları bir araya getirildi ve karıştırıldı. Böylece, Formül Ib ve Formül IIb oluştu.

Formül Ia (FIa), Formül Ib (FIb), Formül IIa (FIIa) ve Formül IIb (FIIb) granüleleri üzerinde aşağıdaki deneyler yapılmıştır.

Granülelerde Akış Hızı Tayini: 20 g granülenin Flowtesteor aletinde akış hızı tayin edildi. Deney 10 kez yinelenip, ortalaması alındı.

Küme Dansitesi Tayini: 10 g granülenin $25 \mathrm{ml}$ lik mezürdeki hacmi ölçüldü, $\mathrm{dk}=\frac{\mathrm{M}_{\mathrm{k}}}{\mathrm{V}_{\mathrm{k}}}\left(\mathrm{g} / \mathrm{cm}^{3}\right)$ formülünden hareketle, her bir formülün küme dansitesi hesaplandı. Deney 5 kez yinelenip ortalaması alınd1.

Tabletlerin Basılması: Yukarıda formülü verilmiş olan, kaydırıcı-kaypaklaştırıcı karışımından, her bir formüle $\% 2$ oranında ilave edilip, uygun büyüklükteki cam bir kavanoz içinde, asimetrik hareketlerle (Tubula karıştırıcısına benzetimli olarak) 10 dakika süre

i) Kollidon 25, BASF, B. Almanya,

1) Erweka, Feucht Granulator, Type FGS, B. Almanya,

k) Ender, Tip, E.Ö., Yerli Yapım.

1) Retsch, Prüfsiebe, B. Almanya.

m) Eleme süresi 20 dak. ve titreşim genliği $2 \mathrm{~mm}$.

n) 10 dak. süre ile ve 25 devir/dak. da.

o) Erweka, Type GDT, B. Almanya. 
ile elle döndürülerek karıştırıldı. Bu granüleler tablet makinasında ${ }^{p}$ $10 \mathrm{~mm}$ çaplı, tekli ve düz yüzlü zımba ile ağırlıkları 325 - 330 mg olacak şekilde basıldı.

Tabletlerin üzerinde yapılan çalışmalar: Hazırlanan tabletlerde, aşağıdaki kontrollar yapılmıştır.

a) Ağırlık Kontrolü: Hazırlanan tabletlerden 20 adet alınarak, ağırlıkları saptandı ve ortalama ağırlıkları hesaplandir ${ }^{r}$.

b) Sertlik Kontrolü: Her bir tabletin, basımdan hemen sonra ve 24 saat sonraki sertlikleri ${ }^{\text {s }}$ tayin edildi. 10 tabletin sertlik ortalamas alındi.

c) Ufalanma-aşınma Kontrolü: 10 adet tablet tartılarak, Roche Friabilatöründe 25 devir/dak. da 5 dakika süre ile döndürüldü. Sonra tabletler teker teker alınıp, birlikte tartıldı. Ağırlık kaybı saptand 1 ve buradan \% kayıp hesaplandi.

d) Dă̆ılma Kontrolü: T.F. 1974'te (28) verilen yönteme göre yapıld ${ }^{*}$. Bu amaçla, pepsin içermeyen $37^{\circ} \pm 2 \mathrm{C}$ lik yapay mide ortamı kullanıldı (29). Deney her defasinda 6 tabletle 3 kez yinelendi.

e) Kalınlık: Her bir tablet grubundan 20 tablet alınarak

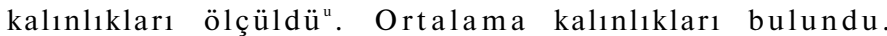

Bulgular istatistiksel olarak karşılaştırılıp değerlendirilmiş, bu amaçla, eşlerarası ve gruplararası farklılıkların önem kontrolü, Student "t", Wilcoxon Eşleştirilmiş iki örnek ve Mann-Whitney testlerine göre yapılmıştırv . Ortalama, bağıl sapma ve ortalamaların, t 0.05 e göre güvenirlik sınırları hesaplanmıştır (30).

\section{TARTIŞMA VE SONUÇ}

Her iki granülenin kırılganlık indeksi hesaplandı̆̆ında Şekil 1 ve 2, melanjörde imal edilmiş granülelerin kırılganlık indeksleri 0.450 \pm 0.0012 iken bu değer, planeter karıştırıda $0.580 \pm 0.006$ olarak bulunmuştur. Buna göre melanjörde imal edilen tablet granülesinin kırılganlı̆̆ı, diğerine göre daha yüksek, yani daha kırılgandır.

p) Korsch, EK-O, No. 9499, B. Almanya,

r) Mettler, H 10, İsviçre.

s) Strong-Cobb, PT-100, J.H. DeLamar and Sons, Inc., A.B.D.

t) Manesty tablet dağılma testi aleti, İngiltere

u) Mikrometre, Kaefer $(0.01 \mathrm{~mm})$, B. Almanya

v) Texas Instruments, TI-55, A.B.D. 


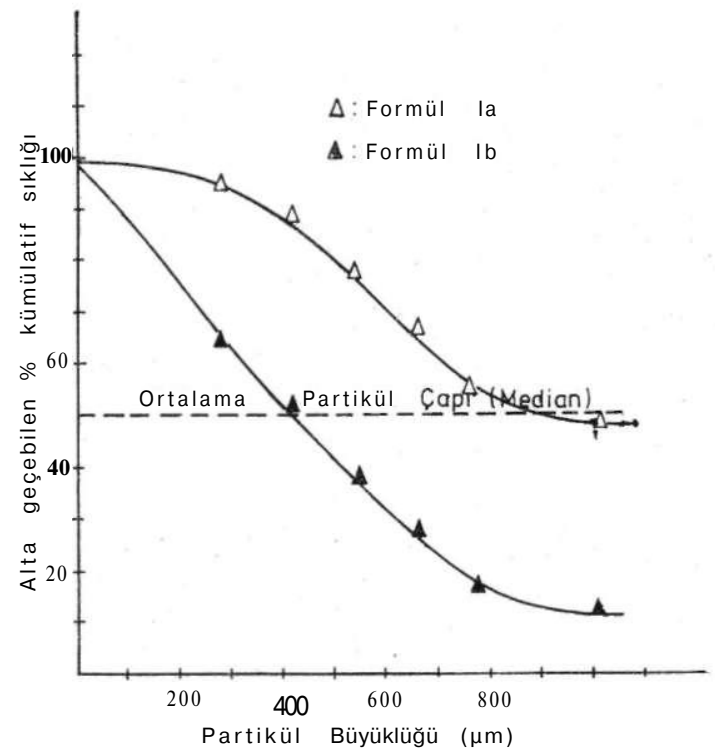

Şek. 1. Melanjörde Hazırlanmış Granülenin Ufalanma-Aşınma İşlemi Uygulandıktan Sonraki ve Uygulanmadan Önceki Partikül Büyüklüğ̈ Dağılımı.

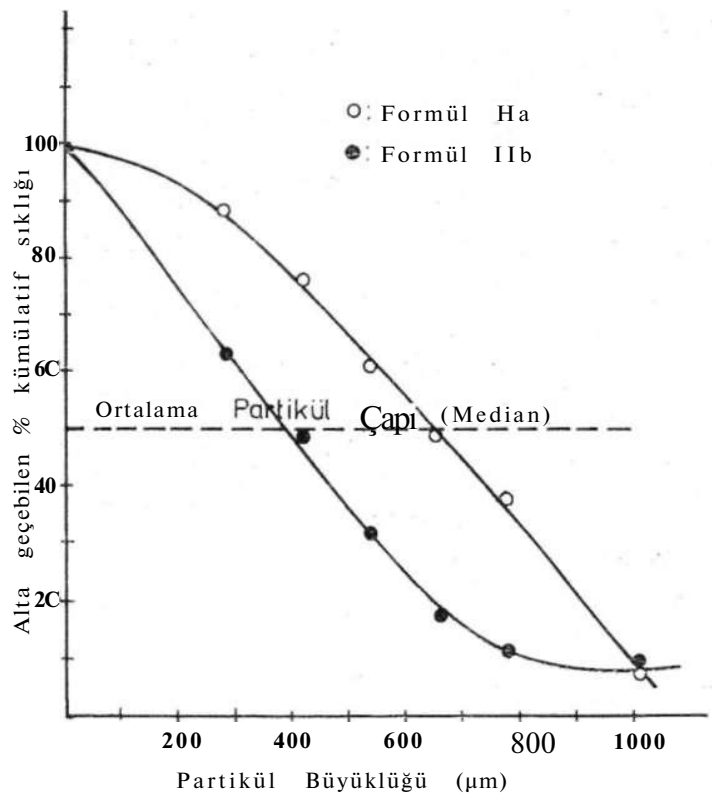

Şek. 2. Planet Karıştırıcıda Hazırlanmış Granülelerin Ufalanma Aşınma İşlemi Uygulandıktan Sonra ve Uygulanmadan Önceki Partikül Büyüklüğü Dağılımı. 
Tablo 1. Farklı gereçlerle hazırlanmış granüllerin küme dansiteleri ve akış hızları.

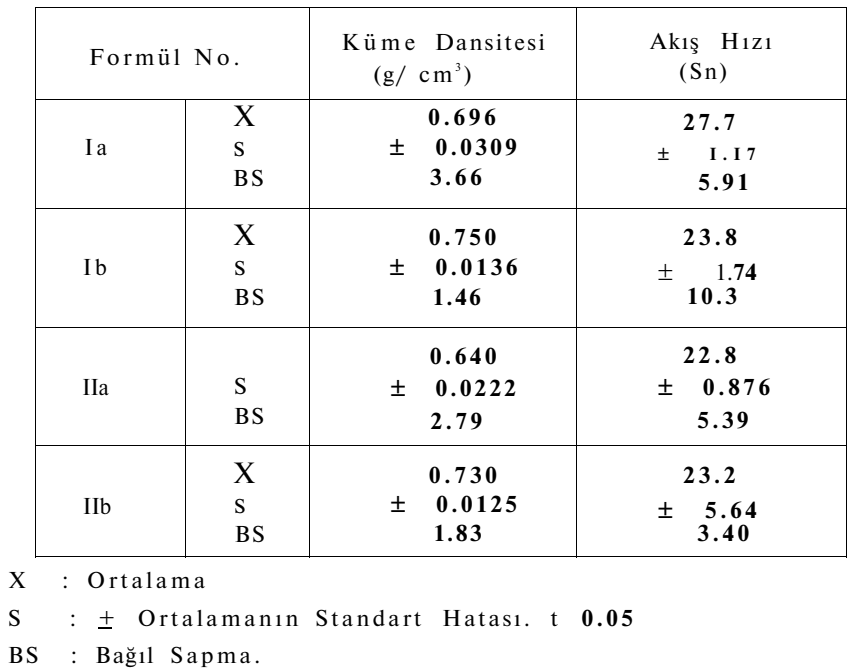

Herbir granitle üzerinde yapılan çalışmaların sonuçları Tablo. 1 de verilmiştir. Buna göre FIa ve FIb de küme dansitelerinde büyüme görülmektedir. FIa ve FIIa arasında anlamlı bir farklılık mevcuttur. $(\mathrm{p}<0.01)$. Aynı farklılık eşler arası küme dansitesi sonuçlarında da önemini korumaktadır. Farklı granülelerin akış hızlarında, granülenin partikül büyüklüğü dağılımının değişmesine paralel bir değişme izlenmiştir. Akış hızları sonuçları karşılaştırıldı̆̆ında, yalnız eşler arasında anlamlı farklılıklar bulunmuştur $(\mathrm{p}<0.05)$. Buna karşın gruplar arası farklılıklar anlamlı değildir.

Tablo 2. de yer alan tablet ağırlıklarında FIIa ve FIIb nin bağıl sapmaları ile güvenirlik sınırları, FIa ve FIb ye nazaran daha küçüktür. Bu da granülenin, partikül büyüklüğü dağılımının planet karıştırıcıda yapılanda daha dar bir sınır içinde olduğunu belgelemektedir Yine aynı tabloda yer alan kalınlık sonuçlarında Fla da $3.18 \pm 0.0567$ $\mathrm{mm}$ iken bu değer, FIIa da $3.05 \pm 0.00587 \mathrm{~mm}$ dir. Buna göre sonuçlar, Tablo 1. deki küme dansitesi sonuçları ile paralellik göstermektedir. Ayrıca planet karıştırıcıda hazırlanan FIIa nın güvenirlik sınırı, FIa ya göre $10 \mathrm{kez}$ daha fazladır. Bu da FIIa nın stabil bir küme dansitesi göstermiş olduğunu belgelemektedir ki, gruplar arası fark çok anlamlıdır $(\mathrm{p}<0.01)$. Aynı fark, FIb ve FIIb de de 
Tablo 2. Farklı gereçlerle hazırlanmış granülelerden basılan tabletlerin fiziko-farmasötik özellikleri.

\begin{tabular}{|c|c|c|c|c|c|c|c|}
\hline \multicolumn{2}{|c|}{ Formül No. } & $\begin{array}{l}\text { Tablet } \\
\text { Ağํliğ } 1 \\
(\mathrm{mg})\end{array}$ & $\begin{array}{l}\text { Tablet } \\
\text { Kalınlığ } \\
\quad(\mathrm{mm})\end{array}$ & $\begin{array}{c}\text { Sertlik } \\
\text { (S.C.U.) }\end{array}$ & $\begin{array}{c}24 \text { Saat Sonraki } \\
\text { Sertlik } \\
\text { (S.C.U.) }\end{array}$ & $\begin{array}{c}\text { Ufalanma } \\
\text { Aşınma } \\
(\%)\end{array}$ & $\begin{array}{c}\text { Dağılma } \\
\text { Süresi } \\
(\mathrm{Sn})\end{array}$ \\
\hline I a & $\begin{array}{l}X \\
\text { S } \\
\text { BS }\end{array}$ & $\begin{array}{r}331.50 \\
+\quad 7.62 \\
4.92\end{array}$ & $\begin{array}{ll} & 3.18 \\
+\quad 0.0567 \\
3.68\end{array}$ & $\begin{array}{l}\quad 8.25 \\
\pm \quad 1.007 \\
26.12\end{array}$ & $\begin{array}{c}10.70 \\
\pm \quad 0.845 \\
11.05\end{array}$ & I. 78 & $\begin{array}{c}48.6 \\
+\quad 18.94 \\
36.93\end{array}$ \\
\hline $\mathrm{Ib}$ & $\begin{array}{l}\text { X } \\
\text { S } \\
\text { BS }\end{array}$ & $\begin{array}{r}328.80 \\
+\quad 3.41 \\
2.22\end{array}$ & $\begin{array}{ll} & 3.14 \\
\pm \quad 0.0162 \\
\\
\text { I.II }\end{array}$ & $\begin{array}{c}9.00 \\
+\quad 0.474 \\
11.28\end{array}$ & $\begin{aligned} 8.55 \\
+0.569 \\
9.32\end{aligned}$ & 0.61 & $\begin{array}{c}61.11 \\
+\quad 6.50 \\
21.38\end{array}$ \\
\hline $\mathrm{H} \mathrm{a}$ & $\begin{array}{l}\text { X } \\
\text { S } \\
\text { BS }\end{array}$ & $\begin{array}{r}312.60 \\
+\quad 1.74 \\
1.19\end{array}$ & $\begin{array}{ll} & 3.05 \\
\pm \quad 0.00587 \\
0.413\end{array}$ & $\begin{array}{l}5.89 \\
+\quad 0.364 \\
13.26\end{array}$ & $\begin{array}{ll} & 5.45 \\
+ & 0.355 \\
& 9.12\end{array}$ & 1.89 & $\begin{array}{c}39.8 \\
+\quad 2.055 \\
10.37\end{array}$ \\
\hline I I b & $\begin{array}{l}\text { X } \\
\text { S } \\
\text { BS } \\
\end{array}$ & $\begin{array}{r}307.00 \\
+\quad 3.82 \\
2.66 \\
\end{array}$ & $\begin{array}{ll} & 3.00 \\
\pm \quad 0.1008 \\
7.19 \\
\end{array}$ & $\begin{array}{c}7.63 \\
\pm \quad 0.472 \\
13.25 \\
\end{array}$ & $\begin{array}{ll} & 7.35 \\
\pm & 0.938 \\
& 7.8 \\
\end{array}$ & 1.93 & $\begin{array}{r}42.05 \\
+\quad 2.71 \\
12.96 \\
\end{array}$ \\
\hline
\end{tabular}


önemini korumaktadır $(\mathrm{p}<0.02)$. Tablet sertliği değerlerini birbirleriyle karşılaştırırırsak, FIb ve FIIb de basımdan hemen sonra, yapılan ölçüm değerlerinde, FIa ve FIIa ya göre bir yükselme görülmektedir. Planet karıştırıcı ile hazırlanan granülede, hemen yapılan ölçme ile, basımdan sonraki 24 saatte yapılan ölçmeler arasında istatistiksel olarak anlamlı farklılıklar bulunamamıştır. Halbuki melanjör ile yapılan granüle formüllerinde ilk ve son ölçmeler arasında anlamlı farklılıklar görülmüştür $(\mathrm{p}<0.05)$. Bu bize basım sırasında sıkışan granüle partiküllerinin konsolide olma yeteneklerinin daha stabil olduğunu göstermektedir (31).

Ufalanma aşınma yüzdeleri, yine planet karıştırıcıda yapılanda eşler arasında önemli bir değişiklik göstermemiştir. Melanjörde yapılanda ise, bu değer; \% 1.78 den \% 0.61 düşmüştür. Bu da melanjörde hazırlanan granülenin partiküllerinin, ufalanmaya daha çok maruz kalmasının bir nedeni olabilir Şekil. 1, Tablo 2.

Dağılma testinde, FIa - FIb ve FIIa - FIIb den oluşan eşler arasında anlamlı bir farklılık bulunamamaıştır. Fakat buna karşın, gruplar arasındaki fark anlamlıdır $(\mathrm{p}<0.05)$. Ayrıca dağılma süreleri ile sertlikler arasında yakın bir ilgi, Tablo 2 değerlerinden gözlenmektedir. Yine planet karıştırıcıda hazırlanan granüleden basılan tabletin dağılma süreleri, diğerine nazaran daha kısadır. Bu da planet karıştırıcı hazırlama tekniğinin, diğerine göre üstünlüğünü belgelemektedir.

Tüm deney sonuçlarının karşılıklı biçimde mukayesesi göstermiştir ki, planet karıştırıcıda hazırlanan granüleden basılan tabletlerin fiziko-farmasötik özelliklerinde, melanjörde hazırlanana k1yasla daha olumlu sonuçlar elde edilmiştir. Bunun nedenlerini şöyle açıklayabilmekteyiz; a) Planet karıştırıcı, granüle imalatı sırasında karışımı daha homojen ve etkin bir biçimde karıştırabilmektedir. Halbuki melanjörde; zaman zaman çalışmaya ara verip, döner bıçakların aralarına ve aletin dip kısmına yapışıp kalan granüle hamurunun kazınıp tekrar döndürülmesi gerekmektedir, b) Planet karıştırıcının, üstü kısmının açık olması nedeniyle, imalat sırasında bağlayıcı ile sslatılan granüle bir yandan kurumaya maruz kalmakta ve üzerine ilave edilen bağlayıcı porsiyonları kısmen aglomerize olmuş tozun kümeleşmeye meylini daha da artırmaktadır. Böylece daha sağlam bir granüle kütlesi elde edilmiş olmaktadır. Melanjörde yapı- 
lan granülede ise, aletin üst kısmının kapalı oluşu nedeniyle, granüle bir yandan sslanıp topraklaşırken bir yandan da kurumaya fırsat bulamamaktadir. Etken madde içermeyen granüleden hareketle yapılan bu çalışmanın, yüksek veya düşük dozda etken madde içeren granüle ile yapıldı̆̆ında nasıl bir sonuç vereceği tartışılabilir.

Farmasötik teknolojideki standartlaştırılmış koşullar, yalnız kullanılan gereçlerin tasarımlarında değil, aynı zamanda özdeş tasarımlı fakat, ayrıntıda veya boyut farklılıklarında dahi önemini korumaktadır. Bu nedenle özdeş koşullarda ilaç üreten bir veya birkaç fabrikanın üretimlerinde meydana çıkabilecek fiziko-farmasötik farklılıkların, ilacın biyoyararlılı̆̆ına kadar uzanabileceği olasıdır.

\section{ÖZET}

$\mathrm{Bu}$ çalışmada farklı gereçlerle (Planet Karıştırıcı ve Melanjör) ve aynı koşullarda hazırlanan granülelerin mekanik dirençlerinde (Friabilite) ne gibi değişikliklerin meydana geldiği saptanmıştır. Bu şekilde hazırlanan granülelerden basılan tabletlerin, fiziko-farmasötik özelliklerinde meydana gelen farklılıklar karşılaştırmalı bir biçimde incelenmiştir. Çalışmanın sonuçları göstermiştir ki; planet karıştırıcı ile hazırlanan granülelerin kırılganlıkları, melanjörde hazırlanan granülelere nazaran daha azdir. Yani mekanik direnci daha yüksektir. Tabletler üzerinde yapılan ağırlık sapması, tablet kalınlığı ve sertliği, ufalanma aşınma ve dağılma testlerinde, planet karıştırıcı ile hazırlanan granüle ile basılan tabletlerin özellikleri daha üstün bulunmuştur. Planet karıştırıcı, yaş granülasyonda, hem daha etkin bir karıştırma sağlamakta ve hem de aletin üst kısmının açık olması nedeniyle imalat sırasında granülenin kendiliğinden ve yavaşça kurumasına neden olmaktadır. Böylece aglomera olan partiküller arasındaki bă̆ oluşumu olumlu yönde etkilenmektedir.

\section{ZUSAMMENFAS S U G}

In dieser Arbeit wurde festgestellt, welche Veraenderungen in den mechanischen Festigkeit (Abriebfestigkeit) der Granulaten vorkommen, die in verschiedenen Geraeten unter den gleichen Umstaenden hergestellt waren. Die physikalisch-pharmazeutische Eigen- 
Schäften der Tablette, die von der auf oben erwaehnter Weise hergestellten Granulaten gepresst waren, wurden vergleicht. Die Ergebnisse der Arbeit hatten gezeigt, dass die Abreibung derim Planetenrührwerk vorberateten Granulaten weniger war als im Laborkneter hergestellten, da die Festigkeit der ersteren waren noch stabiler. Die Gewichtsabweichung, Roll- und Schüttelverschleiss, Dicke, Druckfestigkeit und Zerfallszeit der Tabletten wurden geprüft. Auch dabei wurden die besten Ergebnisse mit Planetenrührwerk erhalten. Beim Feuchtgranulation ist das Planetenrührwerk noch wirkssamer und dabei veranliesst die feuchte Masse langsamer und von sich selber zu trocknen, weil der oberen Teil des Geraetes im Verlauf der Bearbeitung offen ist. Auf diese Weise werden die Brückenentstehung zwischen der agglomerierten Teilchen günstig beeinflusst.

\section{KAYNAKLAR}

1- Lieberman, H.A., and Lachman, L., Pharmaceutical Dosage Forms: Tablets, Vol. 1, Marcel Dekker, New York, (1980).

2- Harwood, C.F. and Pilpel, N., J. Pharm. Sci., 57, 478 (1968)

3- Ganderton, D. and Selkirk, A.B., J. Pharm. Pharmacol., 22, 345 (1969).

4- Jacob, J.T. and Plein, E.M., J. Pharm. Sci., 57, 802 (1968).

5- Solvang, S. and Finholt, P., J. Pharm. Sci., 59, 49 (1970).

6- Geçgil, Ş. and Bayraktar-Alpmen, G., J. Pharm. Belg., 29, 352 (1974).

7- Kafalı-Tarımcı, N., Glibenklamid tabletlerinin çözünme hızında yardımcı maddeler ile zaman, sıcaklık ve nemin etkilerinin incelenmesi, Doktora Tezi, Ankara (1977)-

8- Stanley-Wood, N.G. and Shubair, M.S., J. Pharm. Pharmacol., 31, 429 (1969).

9- Canefe, K., Amoksisilin trihidrat tabletlerinin formülasyon parametreleri, stabilite kinetiği ve çözünme hızı kinetiği ile ilgili çalışmalar, Doçentlik Tezi, Ankara (1980).

10 - Lachman, L., Lieberman, H.A. and Kanig, J.L., The Theory and Practice of Industrial Pharmacy, Lea and Febiger, Philadelphia, 2 nd Ed., p. 630 (1976).

11 - İzgü, E., Genel ve Endüstriyel Farmasi IL, Ayyıldız Matbaası, A.Ș. Ankara, s. 213, (1974)-

12- Brochmann-Hanssen, E. and Medina, J.C., J. Pharm. Sci., 52, 630 (1963).

13 - Arambulo, A.S., Suen-Fu,H. and Deardorff, D.L., J. Am. Pharm. Assoc., Sci. Ed., 42, 692 (1953).

14- Wagner, J.G., J. Pharm. Sci., 50, 359 (1961). 
15- Wagner, J.G., Fundamental of Clinical Pharmacokinetics, Drug Intelligence Publications Inc., Illinois, p. 16, (1979).

16- Sucker, H., Fuchs, P. und Speiser, P., Pharmazeutische Technologie, Georg Thieme Verlag, Stuttgart, S. 156, (1978).

17- A.P.V. Fortbildungskurs über Direkttablettisrung, Mainz, BRD, (1972).

18- Nyström, C., Alex, W. and Malquvist, K., Acta Pharm. Suec, 14, 317 (1977).

19 Nyström, C., Malquvist, K., Mazur, J., Alex, W. and Hölzer, A.W., Acta Pharm. Suec., 15, 226 (1978).

20 - Doelker, E. and Shotton, E.: Ist., Int. Conf. Pharm. Techn., Paris, (1977).

21 - Nyström, C., Symposium on Tablet Techn., Stockholm, (1981).

22 - Sucker, H., Pharm. Acta Suec, 18, 78 (1981).

23 - Gold, G., Duvall, R.N., Palermo, B.T. and Hurtle, R.L., J. Pharm. Sci., 60, 992 (1970-

24 - Fonner, D.R., Banker, G.S. and Swarbrick, J., J. Pharm. Sci., 55, 181 (1966).

25 - Marks, A.M. and Sciarra, J.J., J. Pharm. Sci., 57, 497 (1968).

26 - Hunter, B.M., J. Pharm. Pharmacol., 25, Suppl., 111 P (1973).

27 - Rubinstein, M.H. and Musikabhumma, P., Pharm. Acta Helv., 53, 125 (1978).

28 - Türk Farmakopesi, Milli Eğitim Basımevi, Istanbul, s. 174, (1975).

29- USP XIX, Mack Printing Comp., Philadelphia, p. 765, (1975).

30 - Sümbüloğlu, K., Sağlık Bilimlerinde Araştırma Teknikleri ve İstatistik, Çağ Matbası, Ankara, (1978).

31 - Carstensen, J.T., Lai, T., Flickner, D.W., Huber, E.E. and Zoglio, M.A., J. Pharm. Sci., 65, 992 (1976). 